\title{
Identification of suitable adjuvant for vaccine formulation with the Neospora caninum antigen NcSRS2
}

\author{
Amanda Fernandes Pinheiro ${ }^{\mathrm{a}, 1}$, Bárbara Couto Roloff ${ }^{\mathrm{b}, 1}$, Angelita da Silveira Moreira ${ }^{\mathrm{b}}$, \\ Maria Elisabeth Aires Berne ${ }^{a}$, Renato Andreotti Silva ${ }^{c}$, Fábio Pereira Leivas Leite ${ }^{a, b, *}$ \\ a Departamento de Microbiologia e Parasitologia, Instituto de Biologia, Universidade Federal de Pelotas - UFPel, Pelotas, RS, Brazil \\ ${ }^{\mathrm{b}}$ Núcleo de Tecnologia, Centro de Desenvolvimento Tecnológico, Universidade Federal de Pelotas - UFPel, Pelotas, RS, Brazil \\ ${ }^{\mathrm{C}}$ Centro Nacional Gado de Corte, Empresa Brasileira de Pesquisa Agropecuária - Embrapa, Campo Grande, MS, Brazil
}

\section{A R T I C L E I N F O}

\section{Article history:}

Received 5 July 2017

Received in revised form 12 January 2018

Accepted 18 January 2018

\section{Keywords}

Adjuvant

Vaccine

Cytokine

Neospora caninum

NcSRS2 protein

\begin{abstract}
A B S T R A C T
The parasite Neospora caninum is the main cause of abortion in cattle in many countries around the world, so a vaccine is a rational approach method for the control of the disease. An effective vaccine should be able to prevent both, the horizontal and vertical transmission of $N$. caninum. In this study, the immune vaccinal response of the recombinant protein rNcSRS2 of $N$. caninum expressed in Pichia pastoris and formulated with water-in-oil emulsion, xanthan gum, and alum hydroxide was assessed in an experimental murine model. Groups of $10 \mathrm{Balb} / \mathrm{c}$ mice were subcutaneously inoculated with two doses of prNcSRS2 twenty-one days apart. After the second immunization, four mice from each group were euthanized, and splenocytes were stimulated ex vivo with recombinant protein. The IgG dynamics were evaluated by indirect ELISA, and the splenocytes cytokines transcription by qPCR. All groups elicited specific antibodies against prNcSRS2, with the water-in-oil group showing significantly $(\mathrm{p} \leq .05)$ elevated titers compared to the other groups. The prNcSRS2 protein alone did not induce a significant ex vivo splenic transcription level of IFN- $\gamma$, TNF- $\alpha$, IL-4, IL-10, and IL-12 cytokines, except for IL-17A, and the adjuvant associations with the prNcSRS2 protein induced different cytokine transcription profiles. The water-inoil emulsion modulated the expression of TNF- $\alpha$; the xanthan gum modulated IL-4, IL-10, and IL-12; and alum hydroxide modulated IFN- $\gamma$, TNF- $\alpha$, IL-4, IL-10, and IL-12. In conclusion, it was found that the association of the recombinant prNcSRS2 protein with different adjuvants induced different levels of specific antibody, and a distinct splenic cytokine profile in an adjuvant-dependent manner. The mechanisms of adjuvancity activity is complex, so adjuvant formulation may help in the design of efficient vaccine to control Neosporosis.
\end{abstract}

(c) 2018 Elsevier Ltd. All rights reserved.

\section{Introduction}

Neospora caninum infects a very wide range of livestock and causes important economic losses to the cattle industry [1]. The predominant route of transmission is the endogenous transplacental infection from a pregnant dam [2], and cows of any reproductive age may abort, with most abortions occurring at five to six months of gestation [3]. The development of a vaccine has been proposed as the most suitable control strategy [4]. It has been proposed that the incorporation of tachyzoite host cell adhesion/inva-

\footnotetext{
* Corresponding author at: Centro de Desenvolvimento Tecnológico, Núcleo, Biotecnologia, Campus Universitário, s/n, Caixa Postal 354, Pelotas, RS 96010-900, Brazil.

E-mail_addresses: fabio_leite@ufpel.edu.br, fabio@leivasleite.com.br (F.P.L. Leite).

1 These authors contributed equally to this work.
}

sion protein would be ideal for a $N$. caninum vaccine as effective immune responses could block parasite dissemination and fetal transmission [5]. The surface protein NcSRS2 is involved in the $N$. caninum adhesion process and in host cell invasion [6] and has been regarded as a promising antigen candidate for use in vaccines.

However, recombinant subunit vaccines are often poorly immunogenic and require additional components to stimulate protective immunity [7]. Adjuvants are required to enhance the immunogenicity of antigens, ideally eliciting both humoral and cellular immune responses. A vaccine formulation (antigen/adjuvant) should be developed to activate balance immune responses that are likely to address pathogen evasion strategies. Thus, this study was undertaken to investigate the immune modulatory effect of adjuvants on the immune responses to the $N$. caninum recombinant antigen NcSRS2. 


\section{Materials and methods}

\subsection{Parasite culture and recombinant prNcSRS2 preparation}

The N. caninum isolate NC-1 was propagated in Vero cells using Dulbecco's modified essential medium supplemented (Cultilab, Campinas, Brazil) with 10\% fetal calf serum (FCS, Cultilab, Campinas, Brazil), at $37{ }^{\circ} \mathrm{C}$ in a humidified atmosphere of $5 \% \mathrm{CO}_{2}$. The Pichia pastoris strain X33 (Invitrogen Tech, Carlsbad, CA, USA) was grown in yeast extract peptone dextrose (YPD) medium (1\% yeast extract, $2 \%$ peptone and $2 \%$ D-glucose) or in 1.5\% YPD agar at $30^{\circ} \mathrm{C}$ supplemented with $100 \mu \mathrm{g} / \mathrm{ml}$ of zeocin. Briefly, the recombinant clone (positive by dot blotting and by colony PCR) was selected and inoculated into a 3-L baffled fermenter containing $1 \mathrm{~L}$ of BMMY broth (1\% yeast extract, $2 \%$ peptone, $1.34 \%$ yeast nitrogen base, $0.00004 \%$ biotin, $0.5 \%$ methanol, $100 \mathrm{mM}$ potassium phosphate, $\mathrm{pH} 6.0$ ), and the culture was incubated at $28^{\circ} \mathrm{C}$ for approximately $48 \mathrm{~h}$ until an OD600 of 2-6 was reached. Expression was induced by the addition of methanol (Sigma-Aldrich) at $1 \%$ of the final concentration as previously described [8].

\subsection{Vaccination of the mice}

Female Balb/c, 4-6 weeks of age, were used in all experiments. The mice were housed in eight groups of 10 animals each, and food and water were provided ad libitum. Each mouse was subcutaneously inoculated with a $200-\mu \mathrm{L}$ volume as follows: group 1 with PBS alone, group 2 with $20 \mu \mathrm{g}$ recombinant prNcSRS2, group 3 with $20 \mu$ recombinant NcSRS2 with water-in-oil emulsion (Montanide ISA 61VG, SEPPIC, São Paulo, Brazil), group 4 with $20 \mu \mathrm{g}$ recombinant NcSRS2 adjuvanted with xanthan gum, and group 5 with $20 \mu \mathrm{g}$ recombinant NcSRS2 adjuvanted with 2\% Alhydrogel $^{\circledR}$ (Brenntag Nordic, Haslev, Denmark). Group 6 was given PBS with water-in-oil emulsion; group 7 was given PBS with xanthan gum; and group 8 was given PBS with 2\% Alhydrogel $^{\circledR}$. After 21 days, a boost inoculation was repeated in all groups with the same dose of vaccine. Blood samples were collected through the retroorbital plexus before immunization and on days 7, 14, 21, 28 and 35 post-vaccination. The sera were collected and stored at $-20{ }^{\circ} \mathrm{C}$ until use. The chemical characteristics of xanthan have been previously described [9], and LPS-exposure tests yielded low amounts of endotoxins $(<0.2 \mathrm{EU} / \mathrm{ml}$ ) (data not show).

All protocols were reviewed and approved by the Ethics Committee on Animal Experimentation (CEEA No. 9339) of the Universidade Federal de Pelotas (UFPel). The CEEA of UFPel is accredited by the Brazilian National Council for the Control of Animal Experimentation (CONCEA). The mice used in the study were provided by the animal unit at UFPel.

\subsection{Dynamics of serum $\operatorname{IgG}$ antibodies against prNcSRS2}

Antibody responses were monitored by an indirect ELISA using prNcSRS2 as the antigen. ELISA plates (Polysorp Surface, Nunc, Sigma-Aldrich, St. Louis, MO, USA) were coated overnight at $4{ }^{\circ} \mathrm{C}$ with $50 \mathrm{ng}$ of recombinant protein per well per well in $\mathrm{pH} 9.6$ carbonate-bicarbonate buffer. The plates were then washed three times using PBS-T (10 mM PBS with 0.05\% Tween 20) and blocked using $10 \mathrm{mM}$ PBS with $5 \%$ non-fat milk at $37^{\circ} \mathrm{C}$ for $1 \mathrm{~h}$. To determine the best serum dilution, a checkerboard titration was performed using different antigen concentrations and sera dilutions (pool of the sera from the 35th day). After three washes with PBS-T, the positive and negative control sera and serum samples, all in duplicate, were diluted to 1:100 in $10 \mathrm{mM}$ PBS - T and incubated at $37^{\circ} \mathrm{C}$ for $1 \mathrm{~h}$. After three additional washes, anti-mouse IgG conjugated to peroxidase (Sigma-Aldrich, St. Louis, MO, USA) and diluted at 1:4000 in $10 \mathrm{mM}$ PBS-T was added at $100 \mu \mathrm{L} /$ well, which was followed by incubation at $37^{\circ} \mathrm{C}$ for $1 \mathrm{~h}$. After five washes, $100 \mu \mathrm{L}$ of the substrate (o-phenylenediamine dihydrochloride; OPD tablets, Sigma-Aldrich) in phosphate-citrate buffer $(0.4 \mathrm{mg} / \mathrm{mL})$ containing $0.04 \%$ of $30 \%(\mathrm{v} / \mathrm{v})$ hydrogen peroxide, $\mathrm{pH}$ 5.0, was added to each well, and the plates were incubated in the dark at room temperature for 15 min followed by the addition of $50 \mu \mathrm{L}$ of stop buffer $\left(1 \mathrm{~N} \mathrm{H}_{2} \mathrm{SO}_{4}\right.$ ). Mean optical density (OD) at $492 \mathrm{~nm}$ was determined for all test wells using a microtiter plate reader (Multiskan MCC/340 MKII), and an intra-plate ELISA was performed. The IgG1 and IgG2a isotype levels were evaluated by ELISA using pooled sera. Briefly, the plates were coated as described for ELISA above and then $50 \mu \mathrm{L} /$ well of pooled sera diluted to 1:200 in PBS-T was added to the wells, and the plates were incubated at $37^{\circ} \mathrm{C}$ for $90 \mathrm{~min}$. After this period, the plates were washed three times with PBST, and after adding $50 \mu \mathrm{L} /$ well of anti-mouse $\operatorname{IgG} 1$ isotype antibody (Sigma-Aldrich) diluted $1: 10,000$ in PBS, they were incubated at $37^{\circ} \mathrm{C}$ for $120 \mathrm{~min}$. The same protocol was performed using anti-mouse IgG2 isotype antibody.

\subsection{Ex vivo spleen stimulation and cytokine transcripts}

Thirty-five days after the first inoculation, four mice per group were euthanized, and their spleens were removed. The splenocytes were suspended in Hank's solution, centrifuged and suspended in cell lysis solution (chloride ammonia $0.8 \%$ ). Another wash was performed with Hank's solution, and the cells were suspended in RPMI 1640 (Cultilab, Campinas, Brazil) with 10\% fetal bovine serum (Cultilab, Campinas, Brazil). The cells were incubated for $24 \mathrm{~h}$ at $37^{\circ} \mathrm{C}$ in an atmosphere of $5 \% \mathrm{CO}_{2}$ and then stimulated with either prNcSRS2 $\left(2.5 \mu \mathrm{g} \mathrm{mL}^{-1}\right.$ ) or concanavalin A (Con A, $10 \mu \mathrm{g} \mathrm{mL}^{-1}$ ). The cells were incubated for $24 \mathrm{~h}$ under the same conditions and then collected in TRIzol (Invitrogen Tech, Carlsbad, CA, USA) and stored at $-70^{\circ} \mathrm{C}$. Total RNA was extracted from the cells, and cDNA synthesis was performed from $\sim 300 \mathrm{ng} / \mu \mathrm{L}$ of RNA according to the manufacturer's instructions (Applied Biosystems, Foster City, CA, USA). Quantitative real-time polymerase chain reaction (qPCR) (MxPro-Mx3005P) was used to quantify the cytokines. The reaction was performed in a final volume of $12.5 \mu \mathrm{L}$ containing $1 \mu \mathrm{L}$ of cDNA, $6.25 \mu \mathrm{L}$ of SYBR Green (Invitrogen Tech, Carlsbad, CA, USA), $0.5 \mu \mathrm{M}$ of each primer and $4.25 \mu \mathrm{L}$ of RNase-free water (Gibco-BRL, San Francisco, CA, USA). The samples underwent (1) denaturation at $95^{\circ} \mathrm{C}$ for $5 \mathrm{~min}$; (2) 40 cycles of amplification under the following conditions: $95^{\circ} \mathrm{C}$ for $30 \mathrm{~s}, 60^{\circ} \mathrm{C}$ for $60 \mathrm{~s}$ and $72{ }^{\circ} \mathrm{C}$ for $60 \mathrm{~s}$; (3) final extension at $72{ }^{\circ} \mathrm{C}$ for $5 \mathrm{~min}$. All analyses were performed in duplicate, and a control without cDNA was included to eliminate contamination or unspecific reactions. The value of the threshold cycle (cycle threshold - CT) was defined by the number of PCR cycles required for the fluorescence signal to exceed the threshold detection value. Beta-actin and GAPDH genes were used as endogenous reference controls, but subsequently, $\beta$-actin was selected as the internal reference standard based on its efficiency (M-value of 1.8 and 1.98 for GAPDH and $\beta$-actin, respectively). The primer sequence used was described elsewhere [10].

\subsection{Statistical analysis}

The differences in serum ELISA antibody titers between groups were analyzed by two-way ANOVA, and pair-wise comparisons were made using Tukey's multiple comparisons test, considering p-values of $\leq 0.05$ to be significant. The cytokine results were expressed as the means \pm S.E.M., and statistical analysis was performed by one-way ANOVA followed by Dunnett's multiple comparisons test to investigate statistical differences obtained from 
repeated measures. Each assay was performed in triplicate in at least two separate experiments.

\section{Results}

\section{1. $\operatorname{Ig} G$ serum dynamics}

Seven days after first inoculation, specific anti-rNcSRS2 antibodies were detected in the group inoculated with the prNcSRS2 adjuvanted with the xanthan gum (Fig. 1). Fourteen days after the first inoculation, specific antibodies were detected in the water-in-oil, xanthan and alum groups, but they were significantly higher in the water-in-oil emulsion group than the others. At day twenty-one post vaccination, antibody titers were elevated with the same pattern observed at day 14 post vaccination, and significant increases in antibody response were observed in all groups after the vaccine boost. However, on the 28th day (seven days after the boost), a significant difference in antibody titer $(\mathrm{p} \leq .05)$ was observed in the water-in-oil group compared with the other groups. After the boost, the xanthan gum group had significantly higher antibody titers than the alum and control group. By the 35 th day (14 days after the boost), the water-in-oil and xanthan groups showed significant $(\mathrm{p} \leq .05)$ increases in the antibody titer, whereas the alum group had a decreased titer compared with the 28th day (Fig. 1). The negative control groups (1, 6, 7 and 8) did not react to the antigen (ELISA values below 0.008) throughout the experiment.

When evaluating the IgG isotypes, IgG1 and IgG2a, the waterin-oil group had a significantly $(\mathrm{p} \leq .05)$ higher titer of both isotypes compared with the other groups. The alum group had lower titer than the water-in-oil group, but the IgG2/IgG1 ratios were similar on the 35th day of the experiment with IgG2a/IgG1 ratios of 0.47 and 0.411 for the water-in-oil and alum groups, respectively. Even with low titers, this ratio was observed from day fourteen in the alum group, and the IgG2a increment was observed in the water-in-oil group after the vaccine boost (Fig. 2). The xanthan group showed a IgG2a/IgG1 ratio of 0.13 on the 35th of the experiment, and after day 21 , the $\operatorname{IgG} 1$ levels were significant $(\mathrm{p} \leq .05)$ higher than those of IgG2a. The protein alone had a IgG2a/IgG1 ratio of 0.41 on the 35th day of the experiment, and this tendency was maintained during the studied time points.

\subsection{Cytokine gene expression}

The cytokine transcript levels in the ex vivo spleen stimulation of all mice was assessed by qPCR on the 35th day of the experiment (14 days after the boost). The groups that received protein alone that were associated with the adjuvants demonstrated a very distinct cytokine gene expression profile. The group that received prNcSRS2 alone exhibited a significant $(\mathrm{p} \leq .05)$ upregulation in the transcription level of IL-17A (120-fold increase), which contrasted with the groups adjuvanted with water-in-oil, xanthan or alum that showed a significant transcription downregulation ( $p$ $\leq .05$ ). The association with water-in-oil adjuvant induced a significant $(\mathrm{p} \leq .05)$ elevation in the transcription of TNF- $\alpha$ (11-fold increase) and downregulation in IL-17A transcription by 60 times compared to the group that was inoculated with the protein alone. In the xanthan group, a significant $(p \leq .05)$ increase was found in the transcription levels of the IL-4 (80-fold increase), IL-10 (5.5fold Increase), and IL-12 (4-fold increase) cytokines; this contrasted with IL-17A, which had a 7-fold transcription downregulation compared to the group that received the protein alone. The association of alum with the prNcSRS2 protein upmodulated the transcription for IFN- $\gamma$ by $5.8-$, TNF- $\alpha$ by $3.8-$, IL- 4 by $9-$, IL-10 by $2-$, and IL-12 by 4 -fold compared with the control group. However,
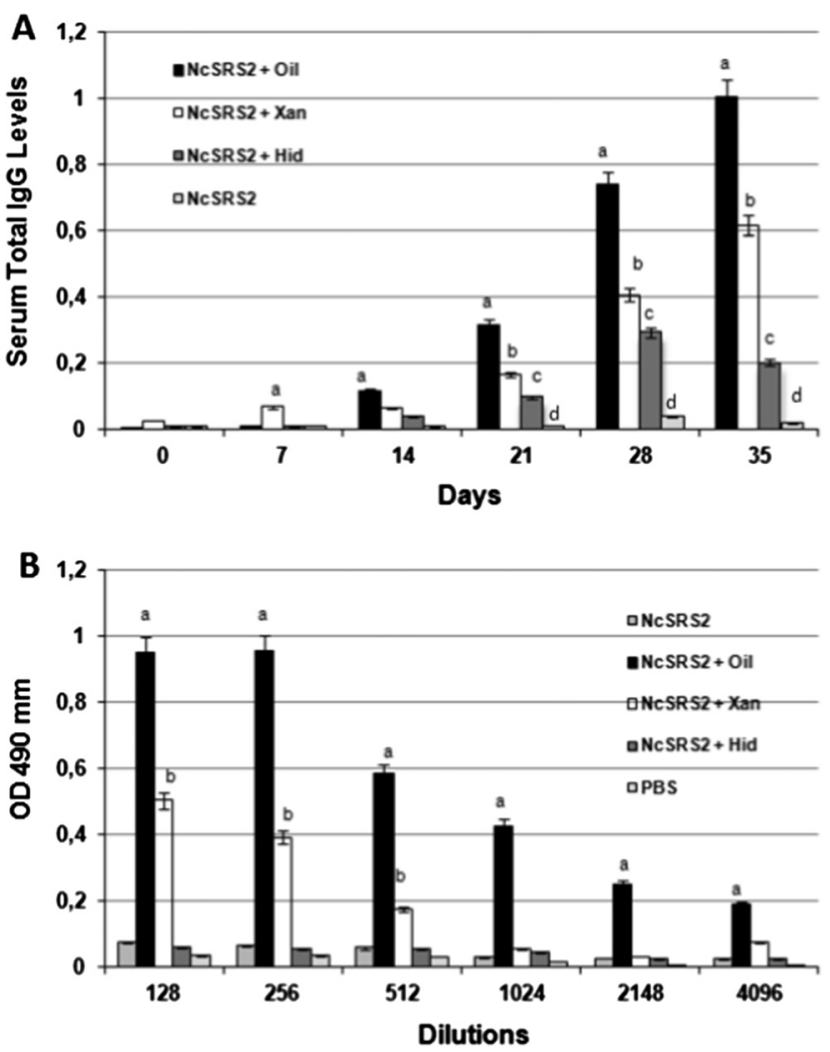

Fig. 1. IgG serum dynamics. A. Serum IgG (diluted 1:100) levels of mice vaccinated with $20 \mu \mathrm{g}$ of recombinant prNcSRS2, formulated with water-in-oil, alumen, and xanthan gum adjuvants. Letters means difference among the groups on the experimental days tested. B. Serum IgG titer of vaccinated mice at 35th day of experiment. Indirect ELISA of sera collected at zero, 7, 14, 21, 28 and 35 days after the first vaccination. Letters means difference of antibodies titers among the groups at day 35 th of the experiment. The data represents the mean \pm S.E.M obtained from samples tested in triplicate, from two independent experiments. Analysis of differences in serum ELISA antibody titers between groups were analyzed by two-way ANOVA and pair-wise comparisons were made using Tukey's Multiple Comparisons test with $\mathrm{p} \leq .05$ considered significant. Letters means difference among the groups.

this association downregulated the transcription level of IL-17A by 5 -fold relative to the protein alone (Fig. 3 ).

\section{Discussion}

The rationale for vaccine development should be guided by an understanding of the relationship between the host/pathogen and immune protection. Thus, antigen selection and its association with an adjuvant in a vaccine should achieve the necessary modulation of the immune response to improve the type of immunity that is necessary to protect the host. Several reports have shown that a Th1-biased immune response against $N$. caninum is required to control tachyzoite proliferation, but a Th2-biased response may also counteract the effects of pro-inflammatory cytokines to safeguard fetal viability and maintain gestation [11,12]. The present study evaluated the humoral immune response as well as the splenic cytokine transcription under an experimental vaccine formulated with recombinant NcSRS2 of $N$. caninum expressed in $P$. pastoris and adjuvanted with water-in-oil, alum hydroxide, or xanthan gum in BALB/c mice.

We observed that the IgG levels, as well as cytokine transcription, followed a different dynamic depending on the adjuvant, confirming that the choice of adjuvant might plays an important role in the vaccine response. 

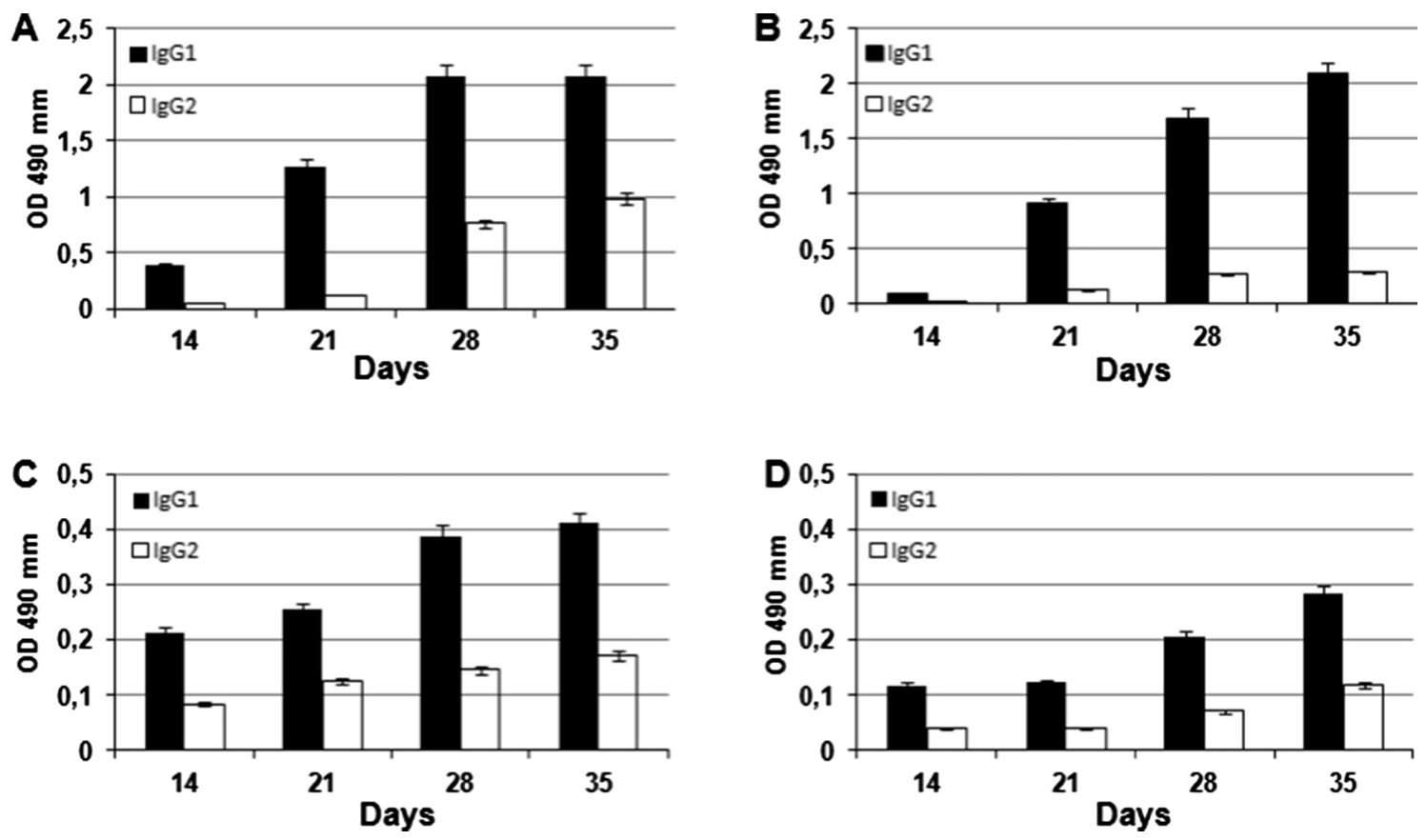

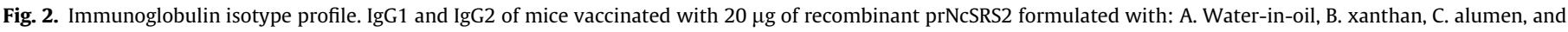

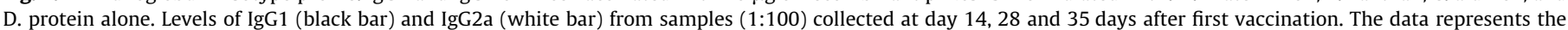
mean \pm S.E.M obtained from samples tested in triplicate, from two independent experiments.

Water-in-oil adjuvants activate the innate immune system to elicit the signal required to initiate an adaptive immune response [7] by forming a depot effect and trapping the antigen at the site of administration, thus increasing the surface area available to the antigen and attracting different kinds of cells, mainly antigen-presenting cells (APC) and macrophages [13]. This kind of adjuvant is commonly associated with mixed Th1/Th2 immune responses [14]. When adjuvanted with water-in-oil, the prNcSRS2 protein yielded higher IgG titers with rising values up to the 35th day of the experiment. Analyzing the ratio $\operatorname{IgG} 2 \mathrm{a} / \operatorname{IgG} 1$ on 35 th day of the experiment, we observed an increase in IgG2a comparing with 28th day, suggesting a modulation towards a mix Th1/Th2 response.

The efficacy conferred by $N$. caninum subunit vaccines in murine models was based on either Th1-directed immune response alone [6], or a mixed Th1/Th2 response [4,8]. However, the same efficacy was not observed in pregnant murine models, where the physiology of gestation prioritizes the Th2 immune response, and reduces the Th1 response [11]. This physiological modulation towards Th2 preserves pregnancy and fetal viability, but compromises vertical transmission protection against the parasite [12]. Thus, an ideal immune vaccinal response to control $N$. caninum should satisfy both, the vertical transmission as well as the maintenance of pregnancy.

Alum is known to be a relatively weak adjuvant for recombinant proteins, but it is effective for conventional vaccine antigens (bacterins and toxoids) [15]. It was traditionally thought to primarily function by forming a long-lasting depot for antigens and by promoting their uptake by APCs, but it is now clear that the innate immune system plays a role in its adjuvanticity [16,17]. In mice, alum induces a greatly polarized Th2 cell-dependent antibody isotypes to practically all protein antigens $[18,19]$. The IgG level in the group adjuvanted with alum was significant lower $(p \leq .05)$ compared with the water-in-oil and xanthan groups, and it did not differ when compared to vaccination without adjuvant (Fig. 1). Surprisingly, this was the group that modulated the transcription of all studied cytokines (Fig. 3), although this result could not explain the observed differences in IgG levels. One may suggest that there may have been differences in the stimulation and activation of the antigen-presenting cells stimulated by the different adjuvants, which may play a role in the observed differences in the immune response.

Xanthan gum is a polysaccharide with a backbone chain that consists of $(1,4) \beta$-D-glucan cellulose derived from Xanthomonas spp., which has viscous properties and is widely used in the food industry [20-25]. The intrinsic adjuvant properties of xanthan gum as a murine lymphocyte activator were originally described in the 1980s, but they have since remained unexplored [26]. Xanthan has been used as an adjuvant in inactivated Aujeszky's disease vaccine with promising results [23], and it has also been used in bioadhesive formulations for intranasal influenza virus immunizations [24]. Different studies have found that the oral administration of xanthan gum has a biological response that enhances antitumor activity in mice through toll-like receptor (TLR)-4 recognition [25], and this pathway leads to the expression of costimulatory molecules that are essential for the induction of an effective adaptive immune response. The IgG level in the group adjuvanted with xanthan was significant higher than that of the alum group and protein alone (Fig. 1). The xanthan was able to modulate an increase in the mRNA transcription of IL- 4 by $\sim 80$-fold more than with prNcSRS2 alone; a similar effect was observed with IL-10 and IL-12 with 2.5- and 4-fold increases, respectively (Fig. 3). Since IgG2 responses are dependent on Th1, mainly by cell-derived IFN-y and IL-12, the reduction of IgG2 responses by xanthan may result from its inhibitory effects on cytokine transcription. The upregulation levels observed for IL-4 and IL-10 transcription may have played a role in the downmodulation of $\operatorname{IgG2}$, since these cytokines have an antagonist effect on IFN-y and IL-12 (Fig. 3).

We speculate that the high IL-17A transcription modulated by prNcSRS2 might bias toward a strong inflammatory response (Fig. 3). Recently, Flynn and Marshall [26] reported the expression of IL-17 during the process of protecting cells from parasite invasion, suggesting that IL-17 plays a role inflammatory response to $N$. caninum infection. Guedes et al. [27], reported that IL-17 were 
IL-17

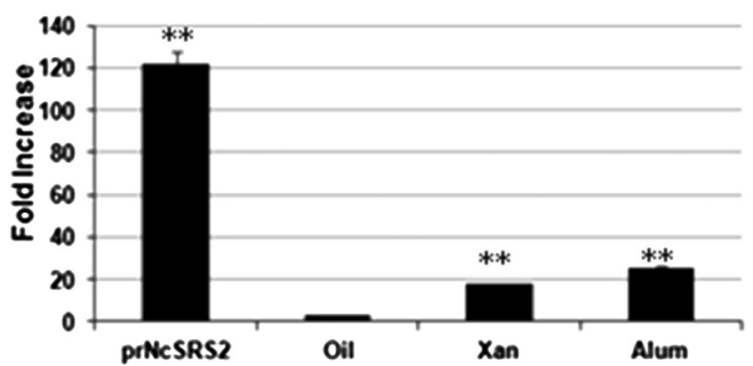

TNF

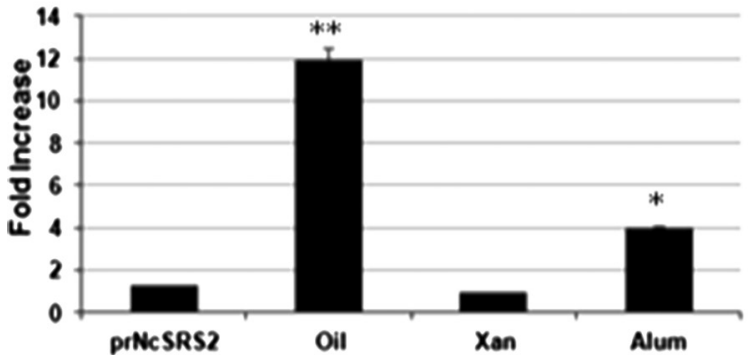

IL-10

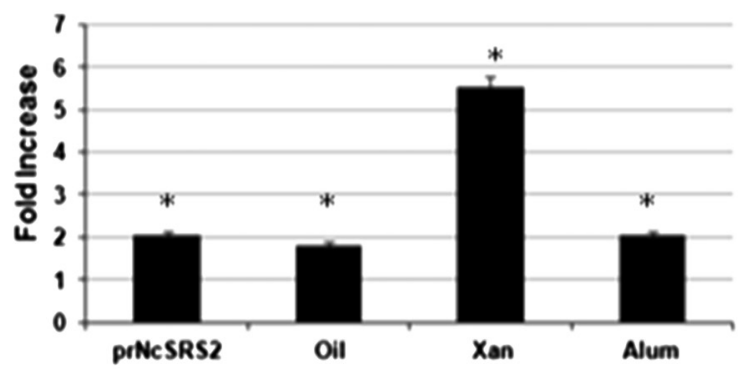

IL-4

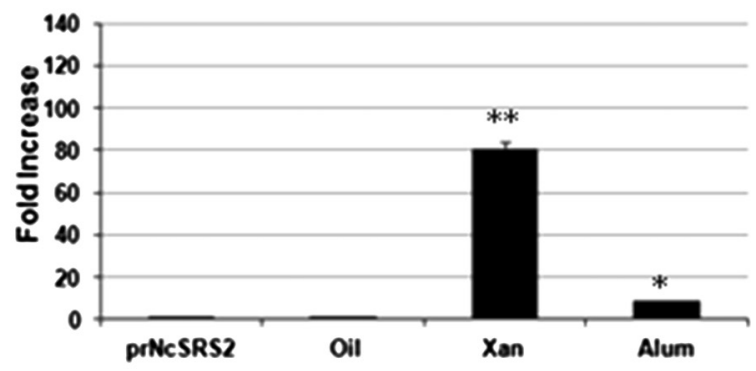

IFN

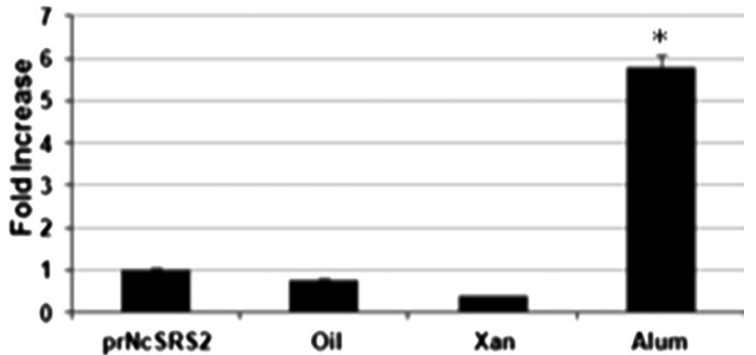

IL-12

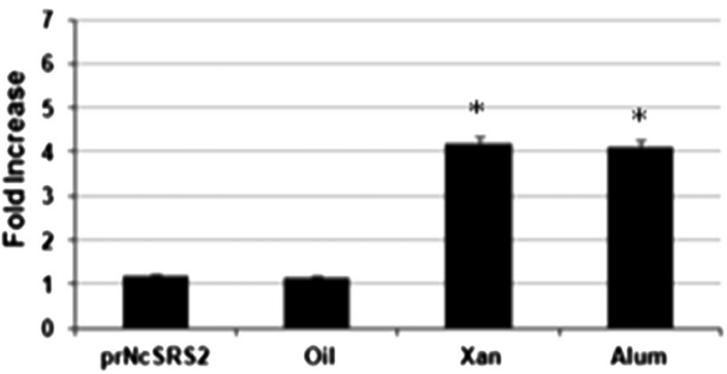

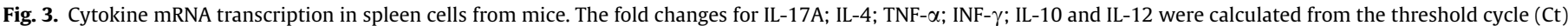

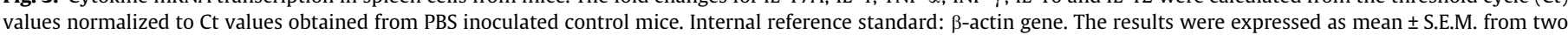

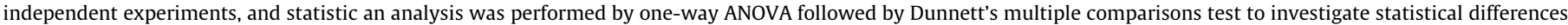
obtained from repeated measures. Asterisks means $\left(^{*}\right) \mathrm{p} \leq .05$, and $\left({ }^{* *}\right) \mathrm{p}<.01$.

able to regulated the Trypanosoma cruzi infection, also [28] and [29] demonstrated that IL-17 modulation by the immune response was important for the control of Leishmania braziliensis and L. donovani infection. More recently we observed that splenocytes from mice inoculated with viable $N$. caninum tachizoites express high mRNA IL-17A transcription, and stimulation of those splenocytes with prNcSRS2 induces elevated IL-17A transcription as well (manuscript in preparation).

A vaccine may counteract the effects of an intense inflammatory response to safeguard fetal viability and maintain gestation, but at same time must to be efficient to prevent proliferation and spread of parasites [18]. Interestingly, significant down regulation in the mRNA transcription of IL-17A was observed when adjuvants were associated with prNcSRS2, this effect might be favorable to a vaccinal response since reducing IL-17 expression may diminish its inflammatory effect during $N$. caninum infection.

Adjuvants have long been of great interest in vaccine development, and in the current study, we studied the roles of distinct adjuvants associated with the prNcSRS2 protein immune response in a mouse experimental model. We demonstrated that, depending on the adjuvant/antigen association, different immune response can be achieved. Even though we observed differences in the immune response due to the tested adjuvants, the activation of the studied cell populations, as well as signaling pathways, by the different adjuvants was outside the scope of our study.

On other hand, there are some limitations to our study. First, the cytokine results are based splenic transcription and not by protein quantification. However, there is a large body of evidence suggesting there is a good correlation between the level of mRNA and its corresponding protein [30-32]. A second limitation is that we did not perform $N$. caninum challenge in the vaccinated experimental groups, such data would have added important information to our results.

The results presented here suggest that the water-in-oil emulsion was the best among the tested adjuvants for use with prNcSRS2, since it provided a significantly higher total IgG titer, a better mixed IgG1/IgG2 response, and a significant reduction on IL-17A expression. Nerveless, the data obtained in this study suggests new directions for complementary studies on the development of $N$. caninum vaccines. 


\section{Acknowledgements}

We thank the Coordenação de Aperfeiçoamento de Pessoal de Nível Superior (CAPES) for a AFP scholarship.

\section{Declaration of interest}

None.

\section{Author contributions}

AFP, BCR, RS, MEB and FPL designed the study and wrote the manuscript. AFP, BCR, AM performed the experiments. All authors contributed to and revised the manuscript.

\section{Funding}

This research did not receive any specific grant from funding agencies in the public, commercial, or not-for-profit sectors.

\section{References}

[1] Dubey JP, Lindsay DS. A review of Neospora caninum and Neosporosis. Vet Parasitol 1996;67:1-59.

[2] Trees AJ, Williams DJ. Endogenous and exogenous transplacental infection in Neospora caninum and Toxoplasma gondii. Trends Parasitol 2005;21:558-61.

[3] Gondim LFP, Pinheiro AM, Almeida MAO. Frequência de anticorpos antiNeospora caninum em búfalos (Bubalus bubalis) criados no estado da Bahia. Revis Bras de Saúde e Produção Animal 2007;8:92-6.

[4] Weston JF, Heuer C, Williamson NB. Efficacy of a Neospora caninum killed tachyzoite vaccine in preventing abortion and vertical transmission in dairy cattle. Prev Vet Med 2012;103:136-44.

[5] Hemphill A, Fuchs N, Sonda S, Hehl A. The antigenic composition of Neospora caninum. Int J Parasitol 1999;29:1175-88.

[6] Gonçalves KN, Andreotti R, Paiva F, Pontes ERJ, Junior MSDCL, Oshiro LM, et al. Interleukin-12 response in NcSRS2 immunization of BALB/c mice against Neospora caninum. Revis Bras de Parasitol Vet 2008;17:215-9.

[7] Seubert A, Monaci E, Pizza M, O’Hagan DT, Wack A. The adjuvants aluminum hydroxide and MF59 induce monocyte and granulocyte chemoattractants and enhance monocyte differentiation toward dendritic cells. J Immunol $2008 ; 180: 5402-12$.

[8] Pinheiro AF, Borsuk S, Berne ME, da Silva Pinto L, Andreotti R, Roos T, et al Expression of Neospora caninum NcSRS2 surface protein in Pichia pastoris and its application for serodiagnosis of Neospora infection. Pathog Glob Health 2013;107:116-21.

[9] Bacelo KL, Hartwig DD, Seixas FK, Schuch R, Moreira AS, Amaral M, et al Xanthan gum as an adjuvant in a subunit vaccine preparation against leptospirosis. Biomed Res Int 2014;2014:636491.

[10] Dummer LA, Araujo IL, Finger PF, Santos AGJ, Rosa MC, Conceição FR, et al. Immune response in mice against recombinant bovine herpesvirus 5 glycoprotein D. Vaccine 2014;32:2413-9.
[11] Entrican G. Immune regulation during pregnancy and host-pathogen interactions in infectious abortion. J Comp Pathol 2002;126:79-94.

[12] Innes EA. The host-parasite relationship in pregnant cattle infected with Neospora caninum. Parasitology 2007;134:1903-10.

[13] Moore KW, de Waal Malefyt R, Coffman RL, O'Garra A. Interleukin-10 and the interleukin-10 receptor. Annu Rev Immunol 2001;19:683-765.

[14] Ott G, Barchfeld GL, Chernoff D, Radhakrishnan R, van Hoogevest P, Van Nest G. MF59. Design and evaluation of a safe and potent adjuvant for human vaccines. Pharm Biotechnol 1995;6:277-96.

[15] Mckee AS, MacLeod MK, Kappler JW, Marrack P. Immune mechanisms of protection: can adjuvants rise to the challenge? BMC Biol 2010;12(8):37.

[16] Lambrecht BN, Kool M, Willart MA, Hammad H. Mechanism of action of clinically approved adjuvants. Curr Opin Immunol 2009;21:23-9.

[17] Marrack P, McKee AS, Munks MW. Towards an understanding of the adjuvant action of aluminium. Nat Rev Immunol 2009:9:287-93.

[18] Petrovsky N, Cooper PD. Carbohydrate-based immune adjuvants. Expert Rev Vaccines 2011;10:523-37.

[19] Coffman RL, Sher A, Seder RA. Vaccine adjuvants: putting innate immunity to work. Immunity 2010;33:492-503.

[20] Shakya AK, Nandakumar KS. Applications of polymeric adjuvants in studying autoimmune responses and vaccination against infectious diseases. J Royal Soc Interf 2013;10:20120536.

[21] Garcia-Ochoa F, Santos VE, Casas JA, Gomez E. Xanthan gum: production, recovery, and properties. Biotechnol Adv 2000;18:549-79.

[22] Ishizaka S, Sugawara I, Hasuma T, Morisawa S, Moller G. Immune responses to xanthan gum. I. The characteristics of lymphocyte activation by xanthan gum. Eur J Immunol 1983;13:225-31.

[23] Roos TB, Moraes CM, Vidor T, Vendruscolo CT, Leite FP. Xantana como adjuvante em vacina contra herpes suíno tipo 1. Vet Foco 2009:6:154-8.

[24] Chiou CJ, Tseng LP, Deng MC, Jiang PR, Tasi SL, Chung TW. Mucoadhesive liposomes for intranasal immunization with an avian influenza virus vaccine in chickens. Biomaterials 2009;30:5862-8.

[25] Erten T, Adams GG, Foster TJ, Harding SE. Comparative heterogeneity, molecular weights and viscosities of xanthans of different pyruvate and acetate content. Food Hydrocoll 2014;42:335-41.

[26] Flynn RJ, Marshall ES. Parasite limiting macrophages promote IL-17 secretion in naive bovine CD4(+) T-cells during Neospora caninum infection. Vet Immunol Immunopathol 2011;144:423-9.

[27] Guedes PM, Gutierrez FRS, Maia FL, Milanezi CM, Silva Grace K, Pavanelli WR, Silva JS. IL-17 Produced during Trypanosoma cruzi infection plays a central role in regulating parasite-induced myocarditis. PLOS Neglected Tropical Diseas 2010;4:1-11.

[28] Pitta R, Romano A, Cabantous S, Henri S, Hammad A, Kouriba B, Argiro L, el Kheir M, Bucheton B, Mary C, El-Safi H, Dessein A. IL-17 and IL-22 are associated with protection against human kala azar caused by Leishmania donovani. J Clin Invest 2009:2379-87.

[29] Novoa R, Bacellar O, Nascimento M, Cardoso TM, Ramasawmy R, Oliveira WN, et al. IL-17 and regulatory cytokines (IL-10 and IL-27) in L. braziliensis Infection. Parasite Immunol 2011;33:132-6.

[30] Line SR, Liu X, de Souza AP, Yu F. Translational signatures and mRNA levels are highly correlated in human stably expressed genes. BMC Genom 2013;14:268.

[31] Hong-wu D, Guang-yu C, Chun-he Y, Chuan-bao L, Yi-ping X, Jia L, et al. Multiple correlations of mRNA expression and protein abundance in human cytokine profile. Mol Biol Rep 2014;41:6985-93.

[32] Fatma MS, Pinto L, García-Piñeres A, Lempicki R, Williams M, Harro C, et al. Comparison of mRNA and protein measures of cytokines following vaccination with HPV- 16 L1 virus like particles. Cancer Epidemiol Biomarkers Prev 2010;19:978-81. 